\title{
Effects of self-isolation and quarantine on loot box spending and excessive gaming - results of a natural experiment
}

\author{
Lauren C Hall ${ }^{1}$, Aaron Drummond ${ }^{\text {Corresp., } 1}$, James D Sauer ${ }^{2}$, Christopher J Ferguson ${ }^{3}$ \\ ${ }^{1}$ School of Psychology, Massey University, Palmerston North, Manawatu, New Zealand \\ 2 Psychology, School of Medicine, University of Tasmania, Hobart, Tasmania, Australia \\ 3 Department of Psychology, Stetson University, DeLand, Florida, United States \\ Corresponding Author: Aaron Drummond \\ Email address: A.drummond@massey.ac.nz
}

COVID-19 has prompted widespread self-isolation and citywide/countrywide lockdowns. The World Health Organisation (WHO) has encouraged increased digital social activities such as video game play to counteract social isolation during the pandemic. However, there is active debate about the potential for video game overuse, and some video games contain randomised purchases (loot boxes) that may psychologically approximate gambling. In this pre-registered study, we examined the effects of self-isolation and quarantine on excessive gaming and loot box spending. We recruited 1,144 (619 Male, 499 Female, 26 Other) Australian, Aotearoa New Zealand, and US residents who were quarantined or self-isolating $(n=447)$ or not $(n=619)$ during the COVID-19 pandemic to a cross-sectional natural experiment. We compared the associations between problem gambling symptomology, excessive gaming and loot box spending for isolated and nonisolated participants. Participants completed the Kessler-10 Psychological Distress Scale, Problem Gambling Severity Index, Internet Gaming Disorder Checklist, a measure of risky engagement with loot boxes, concern about contamination, and reported money spent on loot boxes in the past month, as well as whether they were quarantined or under selfisolation during the pandemic. Although, in our data, excessive gaming and loot box spending were not higher for isolated (self-isolated/ quarantined) compared to non-isolated gamers, the established association between problem gambling symptomology and loot box spending was stronger among isolated gamers than those not isolated. Concerns about being contaminated by germs was also significantly associated with greater excessive gaming and, to a lesser extent, loot box spending irrespective of isolation status. Gamers might be managing concerns about the pandemic with greater video game use, and more problem gamblers may be purchasing loot boxes during the pandemic. These relationships may represent temporary coping mechanisms which abate when COVID-19 ends. Re-examination as the pandemic subsides may be required. More generally, the 
results suggest that social isolation during the pandemic may inflate some pathological gaming effects. We urge caution not to generalise psychological findings from research conducted during the COVID-19 pandemic to be necessarily representative of the magnitude of relationships when not in a pandemic. 
1 Effects of self-isolation and quarantine on loot box spending and excessive gaming - results

2

3

4

5

6 aSchool of Psychology, Massey University, Palmerston North 4424, Manawatu, New Zealand

7 bPsychology, School of Medicine, University of Tasmania, Australia

$8 \quad$ 'Department of Psychology, Stetson University

9

10

11

12

13

14

15

16

17

18

19

20

Word Count: 4,450

21

\section{of a natural experiment.}

\author{
Lauren C. Hall ${ }^{\mathrm{a}}$, Aaron Drummond ${ }^{\mathrm{a}}$, James D. Sauer ${ }^{\mathrm{b}}$, \& Christopher J. Ferguson ${ }^{\mathrm{c}}$
}

*To whom correspondence should be addressed. Email: a.drummond@massey.ac.nz 
Abstract

25

COVID-19 has prompted widespread self-isolation and citywide/countrywide lockdowns. The World Health Organisation (WHO) has encouraged increased digital social activities such as video game play to counteract social isolation during the pandemic. However, there is active debate about the potential for video game overuse, and some video games contain randomised purchases (loot boxes) that may psychologically approximate gambling. In this pre-registered study, we examined the effects of selfisolation and quarantine on excessive gaming and loot box spending. We recruited 1,144 (619 Male, 499 Female, 26 Other) Australian, Aotearoa New Zealand, and US residents who were quarantined or selfisolating $(n=447)$ or not $(n=619)$ during the COVID-19 pandemic to a cross-sectional natural experiment. We compared the associations between problem gambling symptomology, excessive gaming and loot box spending for isolated and non-isolated participants. Participants completed the Kessler-10 Psychological Distress Scale, Problem Gambling Severity Index, Internet Gaming Disorder Checklist, a measure of risky engagement with loot boxes, concern about contamination, and reported money spent on loot boxes in the past month, as well as whether they were quarantined or under selfisolation during the pandemic. Although, in our data, excessive gaming and loot box spending were not higher for isolated (self-isolated/ quarantined) compared to non-isolated gamers, the established association between problem gambling symptomology and loot box spending was stronger among isolated gamers than those not isolated. Concerns about being contaminated by germs was also significantly associated with greater excessive gaming and, to a lesser extent, loot box spending irrespective of isolation status. Gamers might be managing concerns about the pandemic with greater video game use, and more problem gamblers may be purchasing loot boxes during the pandemic. These 
45 relationships may represent temporary coping mechanisms which abate when COVID-19 ends. Re-

46 examination as the pandemic subsides may be required. More generally, the results suggest that social

47 isolation during the pandemic may inflate some pathological gaming effects. We urge caution not to

48 generalise psychological findings from research conducted during the COVID-19 pandemic to be

49 necessarily representative of the magnitude of relationships when not in a pandemic.

50

51 
52

53

54

55

56

57

\section{Introduction}

COVID-19 has prompted widespread non-pharmaceutical public health interventions including self-isolation and citywide lockdowns (Lewnard \& Lo, 2020). Although these measures have many advantages, including a substantial flattening of the disease curve, they may have unintended maladaptive consequences. For instance, self-isolation and quarantine has substantially reduced access to safe and legal social activities. Social support is an essential aspect of mental health, and social isolation can increase psychological distress (Teo \& Valenstein, 2013). Multiplayer video games offer one avenue for online social engagement. In fact, to encourage stay-at-home social activities, the World Health Organisation (WHO) recently partnered with 58 major video game companies to launch the \#PlayApartTogether campaign, encouraging people to stay at home and play video games during the pandemic (Takashi, 2020); despite having codified gaming disorder into their international classification of disease codes in 2018 (World Health Organisation, 2018).

Scholarly debate persists about the potential for video games to foster maladaptive or excessive use (Aarseth et al., 2017; van Rooj et al., 2018). In particular, there is significant disagreement about whether excessive gaming produces, or is a coping mechanism for, psychopathological symptoms such as depression and anxiety ( van Rooj et al., 2018). Irrespective of whether excessive gaming is a symptom or cause of psychopathology, there is clear theoretical rationale for examining the extent to which social isolation associated with pandemic control measures contributes to excessive gameplay. Moreover, people who are more concerned about being contaminated by the virus might also increase gameplay to cope with the anxiety or social isolation due to the pandemic. Here, we examined whether

(a) socially isolated individuals exhibited higher rates of excessive gameplay than less isolated peers, and (b) whether contamination concerns (worry about, and avoidance behaviours of, disease and germs; Burns et al., 1996) were significantly associated with excessive gameplay. 
A distinct but related issue is that the inclusion of certain monetisation mechanics within video

games might contribute to excessive gameplay or spending (on game-related purchases). Some video games contain randomised purchasable rewards (loot boxes) that some scholars have observed may psychologically approximate conventional gambling activities (Drummond \& Sauer, 2018; Griffiths, 2019). Some scholars have also observed that these mechanisms might meet the legal criteria in many jurisdictions, and could potentially be considered a form of bona fide gambling (Drummond et al., 2020;

McCaffery, 2020). This may explain why studies have repeatedly found a small significant association between problem gambling symptomology and spending on loot boxes (Brooks \& Clark, 2019;

Drummond et al., 2019; 2020; Li et al., 2019; Macey \& Hamari, 2019; Zendle \& Cairns, 2018; 2019; social activities, and the increased need for online social activities may have the potential to exacerbate this relationship. Spending on loot boxes therefore appears to be more common among video game players with problem gambling symptoms (Garea et al., 2020). The apparent increase in the number of people engaging with video games during the pandemic may result in increased exposure to, and hence opportunities for the purchasing of, loot boxes. This has prompted concerns about increased spending on loot boxes for certain user groups (Department for Digital, Cultural, Media \& Sport., 2020; Harris, 2020). One study suggests that reducing exposure to loot boxes by removing them from a game appears to reduce spending only among those with higher problem gambling symptoms (Zendle, 2019). Thus it appears that spending by problem gamblers may be specifically impacted by the presence of loot boxes in an increase in either overall spending on loot boxes, or, a specific increase in spending on loot boxes for problem gamblers. Thus, here we examined whether the established association between problem gambling symptomology was stronger for isolated gamers, compared to their non-isolated peers. As we 
99

100

101

102

103

104

105

106

107

108

109

110

111

112

113

114

115

116

117

118

119

120

121

122

123

124

125

126

127

more socially isolated during the pandemic than people who had lower contamination concern, we expected that people with higher contamination concern may have higher spending on loot boxes. Thus, we also examined whether contamination concerns were significantly associated with spending on loot boxes.

\section{Pre-registered hypotheses.}

In this pre-registered study

(https://osf.io/f4cvj/?view only=4643a14cafc34453b05e0041f4156531) we examined participants'

excessive gaming scores, loot box spending, psychological distress, and whether they were self-isolating

(limiting contact with others) or under quarantine (in mandatory self-isolation). We predicted that ${ }^{1}$ :

1. Participants who report being in self-isolation or quarantine will have higher psychological distress (as measured by the K-10), higher spending on loot boxes, higher risky loot box use scores (as measured by the Risky Loot box Index; RLI), higher excessive gaming (as measured by the IGD scale), and higher contamination concern than participants not in self-isolation or quarantine.

2. There will be a significant positive correlation between contamination concern (as measured by the contamination subscale of the Revised Padua Inventory 10) and psychological distress as measured by the $\mathrm{K}-10$.

3. There will be a significant positive correlation between contamination concern and spending on loot boxes, risky loot box use, and excessive gaming scores (as measured by the IGD scale). This effect will be stronger for participants currently in self-isolation or quarantine than for those not in self-isolation or quarantine.

4. There will be a significant positive correlation between the amount of money participants report spending on purchasing loot boxes in the past month and their problem gambling symptoms as measured by the Problem Gambling Severity Index (PGSI).

5. The relationship will be stronger for participants in self-isolation or quarantine than for those not in self-isolation or quarantine.

6. Participants who are categorized as problem gamblers by the PGSI will report spending more money in the past month on loot boxes than participants who are categorized as

\footnotetext{
${ }^{1}$ We intended to also assess the effect of being in citywide lockdowns, but the low number of participants reporting not being in lockdown $(n=69)$ rendered this analysis underpowered, likely invalidating the results. Interested readers can find these results in the online supplementary materials.
} 
128

129

130

131

132

133

134

135

136

137

138

139

140

141

142

143

144

145

146

147

148

149

150

151

152

153

154

moderate-risk gamblers, who in turn will spend more on loot boxes than low-risk gamblers, who in turn will spend more on loot boxes than non-gamblers.

7. Being in self-isolation or quarantine will moderate the relationship between PGSI category and spending on loot boxes, such that problem gambler classification will show a larger difference in spending for participants currently in self-isolation or quarantine than participants not currently in self-isolation or quarantine.

8. There will be a significant positive correlation between the amount of money participants report spending on purchasing loot boxes in the past month and psychological distress as measured by the Kessler Psychological Distress Scale (K-10).

\section{Methods}

\section{Participants}

Using Prolific Academic, we employed a natural experimental design to compare those people

who were isolated due to the pandemic to those people who had not been isolated by the pandemic.

There was no theoretical reason to believe that the pandemic had selectively isolated gamers or problem gamblers at a higher rate than other people, so this created a natural-groups experiment to assess the effects of isolation due to the pandemic on the playing and spending habits of isolated (vs non-isolated) gamers. We therefore surveyed 1,200 participants from Australia, Aotearoa New Zealand and the US on their video game play and gambling. Excluding those who did not play video games $(n=$ 54), and participants who failed attention checks $(n=2)$, our final sample was 1,144 participants (619 Male, 499 Female, 26 Other). Table 1 shows the descriptive statistics of the sample by country. The majority of participants were from the US $(n=930)$, with 173 participants coming from Australia, and 41 coming from Aotearoa New Zealand. Age ranged from 19 to 80 years old $(M=31.4$ years, $S D=10.5$ years). Participants gave informed consent to participate in the study by proceeding to the questionnaire after reading the information sheet which advised them to cease participation if they did not consent to participate in the study. Ethics approval was obtained for human data collection for this study from Massey University's Human Ethics Southern B Committee, Approval number SOB 19/11. 
155

156

157

158

159

160

161

162

163

164

165

166

167

168

169

170

171

172

173

174

175

176

177

\section{Measures}

Our study followed the same design as an earlier study protocol with the inclusion of some additional measures (Drummond et al., 2020). We employed a variety of standardised psychiatric measurement tools to assess participants' wellbeing, problem gambling symptomology, excessive gaming, risky loot box use and concern about contamination. These measures are detailed below.

Psychological distress. The Kessler (K-10) Psychological Distress Scale assessed psychological distress of participants (Slade et al., 2011) and was employed as previously described in Drummond et al. (2020). The K-10 includes 10 items assessing how often (0, none of the time- 5, all of the time) over the past 30 days participants experienced various non-specific aspects of psychological distress (e.g., "During the last 30 days, about how often did you feel hopeless?").

Spending on loot boxes in past month. Data on loot box spending was collected as previously described in Drummond et al. (2020). We asked participants to report approximately how much money (in their country's currency) they had spent on loot boxes in the past month. We converted all values into US dollars using the listed currency conversion rates of the day using Google's currency conversion. We converted all currencies into US dollars on April 21, 2020 using the following exchange rates: \$USD = $0.63 * A U D ; \$ U S D=0.60 * \$ N Z D$. In accordance with our pre-registration we excluded 9 participants $(0.8 \%$ of total data) who spent more than 3.29 SDs (equivalent to a Z-score differing from the mean at $p<.001$; Tabachnick, Fidell, \& Ullman, 2007) greater than the mean ( $\$ 6.08$ USD, SD $=\$ 42.50$ USD) as outliers from analyses of loot box spending. This resulted in the exclusion of any participant who spent more than $\$ 133.58$ USD on loot boxes in the past month. Including these participants did not qualitatively alter the results. 
178 manner as described in Drummond et al. (2020). The scale asks participants to rate their agreement on a

179 standard 7 point likert scale with items assessing their cognitions associated with opening loot boxes

180 (e.g., "Once I open a loot box, I often feel compelled to open another").

Excessive gaming. Data were collected as previously described in Drummond et al., (2020). We

adapted the Internet Gaming Disorder Checklist to assess excessive gaming symptoms (Przybylski et al.,

2017). This checklist was based on the proposed diagnostic criteria for Internet Gaming Disorder (IGD).

Participants indicate how true $(1$, not at all true- 4 , very true) statements were about how gaming had interfered with aspects of their lives (e.g., "I have lost interest in other hobbies or entertainment in order to play games") or emotions (e.g., "I feel irritable, anxious or sad when I am unable to game"). psychiatric scale assessing obsessive compulsive symptomology. The contamination subscale assesses the degree of disturbance a range of common activities which might result in contamination causes participants (0, not at all - 4, very much). Example items include "I find it difficult to touch an object when I know it has been touched by strangers or by certain people" and "I feel my hands are dirty when I touch money." 
201 of varying risk for gambling problems. In accordance with Currie et al.,'s (2013) revised criteria for the

202 PGSI which display better concurrent validity to the original scoring criteria, participants who score 0 on

203 the scale are considered non-problem gamblers; low-risk gamblers score 1-4 on the PGSI; moderate-risk

204 gamblers $=5-7$ on the PGSI and problem gamblers score 8 or higher on the PGSI.

205

206

207

208

209

210

211

212

213

214

215

216

217

218

219

220

221

222

\section{Procedure}

Participants completed the Kessler-10 Psychological Distress Scale (K-10; Slade et al., 2011),

Problem Gambling Severity Index (PGSI; Currie et al., 2013; Holtgraves, 2009), Internet Gaming Disorder

Checklist (IGDC; Przybylski et al., 2017), a measure of risky engagement with loot boxes (Risky Loot Box

Index; RLI; Brooks \& Clark, 2019), and reported money spent on loot boxes in the past month.

Participants reported contamination concern on the Revised Padua Inventory-10 (Burns et al., 1996),

and their isolation status: self-isolation $(n=250)$, quarantine $(n=197)$, or neither $(n=697)$. This created

a natural-groups experiment to examine whether self-isolation or quarantine affected outcomes. We advertised our study on Prolific Academic as a study investigating video games and gambling. Data were collected between the $7^{\text {th }}$ and the $9^{\text {th }}$ of April 2020 (inclusive). At this time, Aotearoa New Zealand had been in stringent lock-downs (Level 4 under their COVID-19 Alert system) since the $25^{\text {th }}$ of March 2020 (Ardern, 2020). Australia and the US had not enacted a federal lockdown response (though individual States had enacted different lockdown restrictions; Morrison, 2020a; Schuchat, 2020). For context, Australia implemented a national boarder closure (with exemptions for returning citizens, permanent residents, and immediate family members) on 20 $0^{\text {th }}$ March 2020 (Morrison, 2020b), and non-U.S. citizens travelling from China, Iran, The European Schengen Area, The United Kingdom and Ireland were banned from entering the US by Presidential Proclamations taking effect between $2^{\text {nd }}$ February 2020 and $16^{\text {th }}$ March 2020 (Liu, 2020; NAFSA, 2020).

Peer) reviewing PDF | (2020:08:51707:1:1:NEW 17 Nov 2020) 
224 (eliminating contact with other people) or quarantined (under mandated self-isolation) and those who were not. We acknowledge that this grouping may overlook important differences in contexts between different forms of isolation (e.g., for participants anxiously awaiting test results), however two important points bear mentioning. First, the study was conducted early in the pandemic outbreaks in these countries, and terminology, especially among the general public, was relatively new, with exact restriction limitations still under development (Cameron, 2020) and some ambiguity in the Federal response in Australia and the US (Morrison, 2020a; Schuchat, 2020). We expecteded this would add noise to participants' self-reported isolation status, resulting in our decision to group all isolated participants together. Second, the self-isolation questions allowed participants to report whether they were in self-isolation or quarantine to their best understanding of these terms. This may result in some measurement error in reporting. However, we expected that variations in the accessibility of participants' usual social activities would be the primary driver of increased digital media exposure.

Thus, we believe our approach offers a valid way to investigate the effects of increased perceived isolation. A more fine-grained study investigating whether effects are similar across different kinds of isolation using objective measures of such isolation would no-doubt be worthwhile. Nonetheless, our results provide early evidence that participants' perceived isolation status was associated with changes in some gaming-gambling relationships. to participants as "including mandated social distancing, business closures, curfews, stay home orders or other movement restrictions") in cities where movement and gathering restrictions were in place) and those who were not. However, very few participants were not in lockdown ( $n=69, \sim 6 \%$ of our total data). Thus, estimates for non-lockdown participants are underpowered and, therefore, unreliable. 
247 pre-registered comparisons between participants in lockdown and participants not in lockdown in the

248 online supplementary materials with appropriate caveats. At the time of data collection, Aoteroa New

249 Zealand had implemented a Nationwide lockdown which had been in effect for approximately 14 days.

250 Federal lockdown responses had not been introduced in Australia, or the US, creating divergent state-

251 based responses (Morrison, 2020a; Schuchat, 2020). We acknowledge that an examination of different

252 stringencies of lockdown (e.g., Stage 2 versus Stage 4 lockdowns) would constitute a worthwhile follow253 up study.

254

255

256

257

258

259

260

261

262

263

264

265

266

267

268

269

\section{Results}

Participants played video games, on average, most days $(M=2.31, S D=0.83)$. This was likely

due to the fact that the study was advertised as a study on video game use and gambling, and therefore attracted participants who played video games. On average, participants reported spending \$29.63 USD $(S D=\$ 56.27$ USD; Range $=\$ 0-\$ 500$ USD) on video games and $\$ 2.98$ USD (SD = \$11.48 USD; Range $=\$ 0-$ $\$ 107.10$ USD) on loot boxes in the previous month. Although these averages appear small, it is worth noting that this was due to a large number of participants not purchasing video games $(n=578)$ or loot boxes $(n=989)$ in the past month, together with the wide ranges for these variables.

Contrary to predictions, psychological distress was actually higher among people not in selfisolation or quarantine $(M=24.88, S D=8.65)$ than those in self-isolation or quarantine $(M=23.53, S D=$ 8.68), $t(1,142)=2.57, p=.010, d=0.16$, though this was a negligible difference (Ferguson, 2009; Sauer \& Drummond, 2020). We found no evidence that IGDC scores differed between participants in selfisolation/quarantine $(M=7.94, S D=5.59)$ and participants not in self-isolation/quarantine $(M=8.28, S D$ $=5.55), t(1,142)=0.97, p=.330, d=0.16$. We also found no evidence of differences in spending on loot boxes between participants in self-isolation/quarantine ( $M=\$ 3.15$ USD, $S D=\$ 11.38$ USD) and those not $(M=\$ 2.86$ USD, $S D=\$ 11.56$ USD), $t(1,133)=0.42, p=.678, d=0.02$. There was no evidence of a 
270

271

272

273

difference in risky loot box use scores between participants who were isolating $(M=13.53, S D=8.16)$

and those not $(M=13.52, S D=8.00), t(1,142)=0.02, p=.984, d=0.01$. Similarly, contamination concern scores were not statistically different between those in self-isolation/quarantine $(M=12.80, S D=9.55)$ to those $\operatorname{not}(M=13.77, S D=9.72), t(1,142)=1.66, p=.098, d=0.10$.

Collapsed across isolation status, contamination concern was moderately associated with distress, $r=.319, p<.001$, and weakly associated with loot box spending, IGDC, and RLI (see Table 2). Though weak, relationships between contamination concern and IGDC and RLI both exceeded criteria for the smallest effects likely to bear clinical relevance (Ferguson, 2009), suggesting contamination concern may be a clinically significant contributor to excessive engagement with both gaming and monetized in-game reward mechanisms. We compared correlation strengths using Fischer's Z-tests (Weaver \& Wuensch, 2013). Relationships were generally similar for people in self-isolation or quarantine though the association between $\mathrm{RLI}$ and contamination concern was significantly stronger for participants who were self-isolated or quarantined than those who were not (Table 2).

Problem gambling symptomology was associated with higher loot box spending, $r_{s}=.279, p<$ .001 ; with a stronger association for participants who were self-isolated or quarantined, $r_{s}=.366, p<$ .001 , than those who were not, $r_{s}=.209, p<.001, \mathrm{Z}=2.825, p=.005$. Figure 1 shows the association between loot box spending and PGSI scores, split by isolation status.

When classified into risk groups, a 2-way ANOVA showed a main effect of problem gambler status, such that problem gamblers spent more than lower risk gamblers on loot boxes (Figure 2). However, there was no evidence that self-isolation or quarantine altered this relationship. Finally, loot box spending was weakly associated with psychological distress, $r_{s}=.103, p<.001$.

\section{Discussion}


We investigated whether self-isolation or quarantine, or contamination concerns were

293

294

295

296

297

298

299

300

301

302

303

304

305

306

307

308

309

310

311

312

313

314

315

associated with greater excessive gaming, loot box spending or psychological distress. Contrary to

predictions, compared to those not self-isolated or quarantined, participants in self-isolation or

quarantine showed negligiblly lower psychological distress, but no differences in loot box spending, loot

box engagement, or excessive gaming. We found no evidence that self-isolation resulted in greater

excessive gameplay or expenditure on loot boxes generally. It is unclear why lower psychological distress

scores were observed for those in self-isolation or quarantine. Perhaps those in self-isolation or

quarantine may perceive their health risks to be lower due to their isolation, and this offset any distress

associated with isolation. Nonetheless, the effect size was negligible in magnitude, and unlikely to be of

clinical importance (Ferguson, 2009).

However, higher contamination concern was associated with small-to-moderately higher

excessive gaming and risky loot box engagement scores, and small increases in loot box spending. These

effects were generally similar for participants who were self-isolating or in quarantine and those who

were not, with the exception that the relationship between risky loot box use and contamination

concern was stronger for people self-isolating or in quarantine than those not. People may be engaging

with video games to manage their contamination concerns about the COVID-19 pandemic. Of course,

individuals may engage in a range of other activities (e.g., conventional gambling, online shopping,

increased time streaming movies/ T.V. shows, etc.) as a means of managing contamination concern and social isolation due to the pandemic.

The established relationship between problem gambling symptomology and loot box spending

(Garea et al., 2020) was stronger for those in self-isolation or quarantine than those not, demonstrating

closer agreement between problem gambling symptom scores and loot box spending. Indeed the

relationship between problem gambling symptomology and loot box spending was moderate for isolated gamers compared to small for non-isolated gamers.

Peer) reviewing PDF | (2020:08:51707:1:1:NEW 17 Nov 2020) 
However, when PGSI scores were used to categorise gamblers into discrete risk categories (e.g.,

317 low-risk, medium-risk, problem gamblers), average spending within categories was similar for self-

318 isolated or quarantined participants and those not in isolation or quarantine. Since average spending did

319 not increase for problem-gamblers in self-isolated or quarantined (vs. non self-isolated or non-

320 quarantined), it appears that although the correlation between raw PGSI scores and loot box spending

321 become more closely aligned for isolated gamers, how much they individually spend when devolved into

322 risk categories does not substantially increase. Orford et al. (2010) suggest that gambling disorder is

323 more appropriately viewed as a continuum rather than as discrete risk-groups, and the lack of

324 differences between risk categories juxtaposed against a significant increase in the strength of the

325 association between raw PGSI scores and spending may reflect a loss of variability in PGSI scores when

326 this continuous measure is devolved into a categorical variable.

Whether these effects persist when self-isolation and quarantine periods end is unknown. These

increases may plausibly represent temporary coping mechanisms which will abate when the threat of

COVID-19 ends. Alternatively, given the prolonged pandemic activity worldwide, they may persist as the

acquisition of new gambling-like behaviours. Re-examination as the pandemic subsides may be required

to determine whether any effects are temporary or long lasting. If there are prolonged mental health

effects of the pandemic, then this may plausibly result in similar long-term changes in the ways people interact with video games.

More generally, our results suggest that isolation due to the COVID-19 pandemic may act as a moderator for other relationships in pathological gaming research, inflating the size of some previously observed relationships (Garea et al., 2020). We therefore urge researchers to exercise caution in interpreting the size of effects from data gathered during the pandemic in these areas of research. 
340 suggest that researchers in general carefully consider the potential impact of the pandemic on their 341 data. to the Padua Contamination Concern index as a state or trait based measure. It is thus unclear whether

344 the associations between the contamination concern scale, loot box purchasing, excessive gaming and risky loot box use measures imply that changes in concerns about contamination are causing changes in these outcomes, or if, more generally, people high in trait contamination concern tend to have higher scores on these measures. Our interpretation (and we admit that it is speculative) is that both may be distracting behaviours (including spending behaviours) during a global pandemic. Future work should examine this possibility and its alternatives more deeply.

\section{Conclusion}

This natural groups experiment examined eight hypotheses relating to the effects of the COVIDdata suggest that contamination concern is associated with higher excessive gaming and risky loot box engagement, and to a lesser extent, loot box spending. Problem gambling symptomology is associated with greater loot box spending, and this effect is appreciably stronger among people who are currently self-isolating or in quarantine. Future work should examine whether the differences in the strength of the relationship between loot box spending and problem gambling symptomology for gamers who were isolated during the pandemic remains after the pandemic subsides.

\section{Funding}


363 managed by Royal Society Te Apārangi. https://www.royalsociety.org.nz/what-we-do/funds-and-

364 opportunities/marsden The funders had no role in study design, data collection and analysis, decision to 365 publish, or preparation of the manuscript.

\section{Author Contributions}

367 LCH: Conceptualization, Data curation, Formal analysis, Methodology, Writing - original draft, Writing 368 review \& editing.

369 AD: Conceptualization, Data curation, Formal analysis, Funding acquisition, Methodology, Writing 370 original draft, Writing - review \& editing.

371 JDS: Conceptualization, Data curation, Formal analysis, Funding acquisition, Methodology, Writing 372 review \& editing.

373 CJF: Conceptualization, Data curation, Formal analysis, Funding acquisition, Methodology, Writing 374 review \& editing.

Aarseth, E., Bean, A.M., Boonen, H., Colder Carras, M., Coulson, M., Das, D., Deleuze, J., Dunkels, E.,

377 Edman, J., Ferguson, C.J. and Haagsma, M.C., 2017. Scholars' open debate paper on the World Health Organization ICD-11 Gaming Disorder proposal. Journal of Behavioral Addictions, 6(3), pp.267-270.

Available at https://www.beehive.govt.nz/release/new-zealand-moves-covid-19-alert-level-3-then-leveland gambling-related cognitions. Addictive behaviors, 96, pp.26-34. 
384 Burns, G.L., Keortge, S.G., Formea, G.M. and Sternberger, L.G., 1996. Revision of the Padua Inventory of 385 obsessive compulsive disorder symptoms: Distinctions between worry, obsessions, and compulsions. 386 Behaviour research and therapy, 34(2), pp.163-173.

387 Cameron. B. 2020. Captaining a Team of 5 Million: New Zealand Beats Back COVID-19, March - June 388 2020. Innovations For Successful Societies. Trustees of Princeton University. Available at 389 https://successfulsocieties.princeton.edu/sites/successfulsocieties/files/NewZealand_COVID_FInal.pdf 390 (accessed 30 September 2020).

391 Currie, S.R., Hodgins, D.C. and Casey, D.M., 2013. Validity of the problem gambling severity index 392 interpretive categories. Journal of gambling studies, 29(2), pp.311-327. boxes. Available at: https://www.gov.uk/government/news/government-to-launch-call-for-evidenceinto-loot-boxes

Drummond, A. and Sauer, J.D., 2018. Video game loot boxes are psychologically akin to gambling. Nature Human Behaviour, 2(8), pp.530-532. gambling, excessive gaming, psychological distress and spending on loot boxes in Aotearoa New 400 Zealand, Australia, and the United States-A cross-national survey. Plos one, 15(3), p.e0230378. game users with gambling problems?. Addiction, 114(5), pp.935-936. regulated as gambling. Nature Human Behaviour, pp.1-3. 
405 Ferguson, C., 2009. An Effect Size Primer: A Guide for Clinicians and Researchers. Professional

406 Psychology: Research and Practice, 40(5), pp.532-538.

407 Garea, S., Drummond, A., Sauer, J.D., Hall, L.C. and Williams, M., 2020. Meta-Analysis of the Relationship

408 between Problem Gambling, Excessive Gaming and Loot Box Purchasing. PsyArXiv, DOI:

$409 \quad$ 10.31234/osf.io/ug4jy

410 Griffiths, M. D. (2018). Is the buying of loot boxes in video games a form of gambling or gaming?.

411 Gaming Law Review, 22(1), 52-54.

412 Harris C., 2020. Isolation will fuel gambling addiction. We must protect those at risk. The Guardian,

413 March 27. Retrieved from https://www.theguardian.com/commentisfree/2020/mar/27/isolation-will-

414 fuel-gambling-addiction-we-must-protect-those-at-risk

415 Holtgraves, T., 2009. Evaluating the problem gambling severity index. Journal of gambling studies, 25(1), 416 p.105.

417 Lewnard, J.A. and Lo, N.C., 2020. Scientific and ethical basis for social-distancing interventions against

418 COVID-19. The Lancet. Infectious diseases, 20(6), p.631.

419 Li, W., Mills, D. and Nower, L., 2019. The relationship of loot box purchases to problem video gaming 420 and problem gambling. Addictive behaviors, 97, pp.27-34.

421 Macey, J. and Hamari, J., 2019. eSports, skins and loot boxes: Participants, practices and problematic

422 behaviour associated with emergent forms of gambling. New Media \& Society, 21(1), pp.20-41.

423 Liu, EC. 2020. COVID-19: Federal Travel Restrictions and Quarantine Measures. 28 May 2020.

424 Congressional Research Service. Available at https://crsreports.congress.gov/product/pdf/LSB/LSB10415

425 (accessed 28 September 2020). LSB10415.

Peer) reviewing PDF | (2020:08:51707:1:1:NEW 17 Nov 2020) 
426 McCaffrey, M. (2019). The macro problem of microtransactions: The self-regulatory challenges of video

427 game loot boxes. Business Horizons, 62(4), 483-495.

428 Morrison, S. 2020a. Update on coronavirus measures, Media Stataement . 22 March 2020. Available at

429 https://www.pm.gov.au/media/update-coronavirus-measures-220320 (accessed 28 September 2020).

430 Morrison, S. 2020b. Border Restrictions, Media Release . 19 March 2020. Available at

431 https://www.pm.gov.au/media/border-restrictions (accessed 28 September 2020).

432 NAFSA. 2020. COVID-19 Restrictions on U.S. Visas and Entry. 23 September 2020. Available at

433 https://www.nafsa.org/regulatory-information/covid-19-restrictions-us-visas-and-entry (accessed 28

434 September 2020).

435 Orford J, Wardle H, Griffiths M, Sproston K, Erens B. PGSI and DSM-IV in the 2007 British Gambling

436 Prevalence Survey: Reliability, item response, factor structure and inter-scale agreement. International

437 Gambling Studies. 2010 Apr 1;10(1):31-44.

Przybylski, AK, Weinstein, N, Murayama, K. 2017. Internet gaming disorder: Investigating the clinical

relevance of a new phenomenon. American Journal of Psychiatry, 174(3), pp.230-236.

Sauer JD, Drummond A. Boundary Conditions for the Practical Importance of Small Effects in Long Runs:

441 A Comment on Funder and Ozer (2019). Advances in Methods and Practices in Psychological Science.

4422020 Oct 7:2515245920957607.

443 Schuchat, A. 2020. Public Health Response to the Initiation and Spread of Pandemic COVID-19 in the

444 United States, February 24-April 21, 2020, May 8, 2020. Available at

445 https://www.cdc.gov/mmwr/volumes/69/wr/mm6918e2.htm (accessed 28 September 2020). 
446 Slade, T., Grove, R. and Burgess, P., 2011. Kessler psychological distress scale: normative data from the

4472007 Australian National Survey of Mental Health and Wellbeing. Australian \& New Zealand Journal of

448 Psychiatry, 45(4), pp.308-316.

449 Tabachnick BG, Fidell LS, Ullman JB. 2007. Using multivariate statistics. Boston, MA: Pearson.

450 Takahasi, D., 2020. WHO and game companies launch \#PlayApartTogether to promote physical

451 distancing. Venture Beat. Available at: https://venturebeat.com/2020/03/28/who-and-game-

452 companies-launch-playaparttogether-to-promote-physical-distancing/

453 Teo, A.R., Choi, H. and Valenstein, M., 2013. Social relationships and depression: ten-year follow-up

454 from a nationally representative study. PloS one, 8(4), p.e62396.

455 van Rooij A.J., Ferguson C. J., Carras M.C., Bean A. M., Helmersson, B., Etchells, P.J., Kaye, L.K., Mills, K.L.,

456 Lundedal, N.K., Turner, N.E. and Przybylski A.K., 2018. A weak scientific basis for gaming disorder: Let us

457 err on the side of caution. Journal of behavioral addictions, 7(1), p.1.

458

459

460

461

462

463

464

465
Weaver, B. and Wuensch, K.L., 2013. SPSS and SAS programs for comparing Pearson correlations and OLS regression coefficients. Behavior research methods, 45(3), pp.880-895.

World Health Organization, 2018. International classification of diseases for mortality and morbidity statistics (11th Revision). Retrieved from https://icd.who.int/browse11/l-m/en

Zendle D. 2019. Problem gamblers spend less money when loot boxes are removed from a game: a before and after study of Heroes of the Storm. PeerJ. 29(7), e7700.

Zendle, D. and Cairns, P., 2018. Video game loot boxes are linked to problem gambling: Results of a large-scale survey. PloS one, 13(11), p.e0206767.

Peer) reviewing PDF | (2020:08:51707:1:1:NEW 17 Nov 2020) 
466 Zendle, D. and Cairns, P., 2019. Loot boxes are again linked to problem gambling: Results of a replication 467 study. PloS one, 14(3), p.e0213194.

468 Zendle, D., Cairns, P., Barnett, H. and McCall, C., 2020. Paying for loot boxes is linked to problem 469 gambling, regardless of specific features like cash-out and pay-to-win. Computers in Human Behavior, 470 102, pp.181-191. 


\section{Figure 1}

Association between Problem Gambling Symptomology (PGSI score) and Loot Box Spending in \$USD.

Data are presented separately for gamers who were not self-isolated/quarantined $(A)$ and who were self-isolated/quarantined (B). Each data point represents a single participant's responses. The trend lines indicate the positive correlations between spending on Loot Boxes and PGSI scores, with a stronger association for participants who were self-isolated or quarantined than those who were not. 

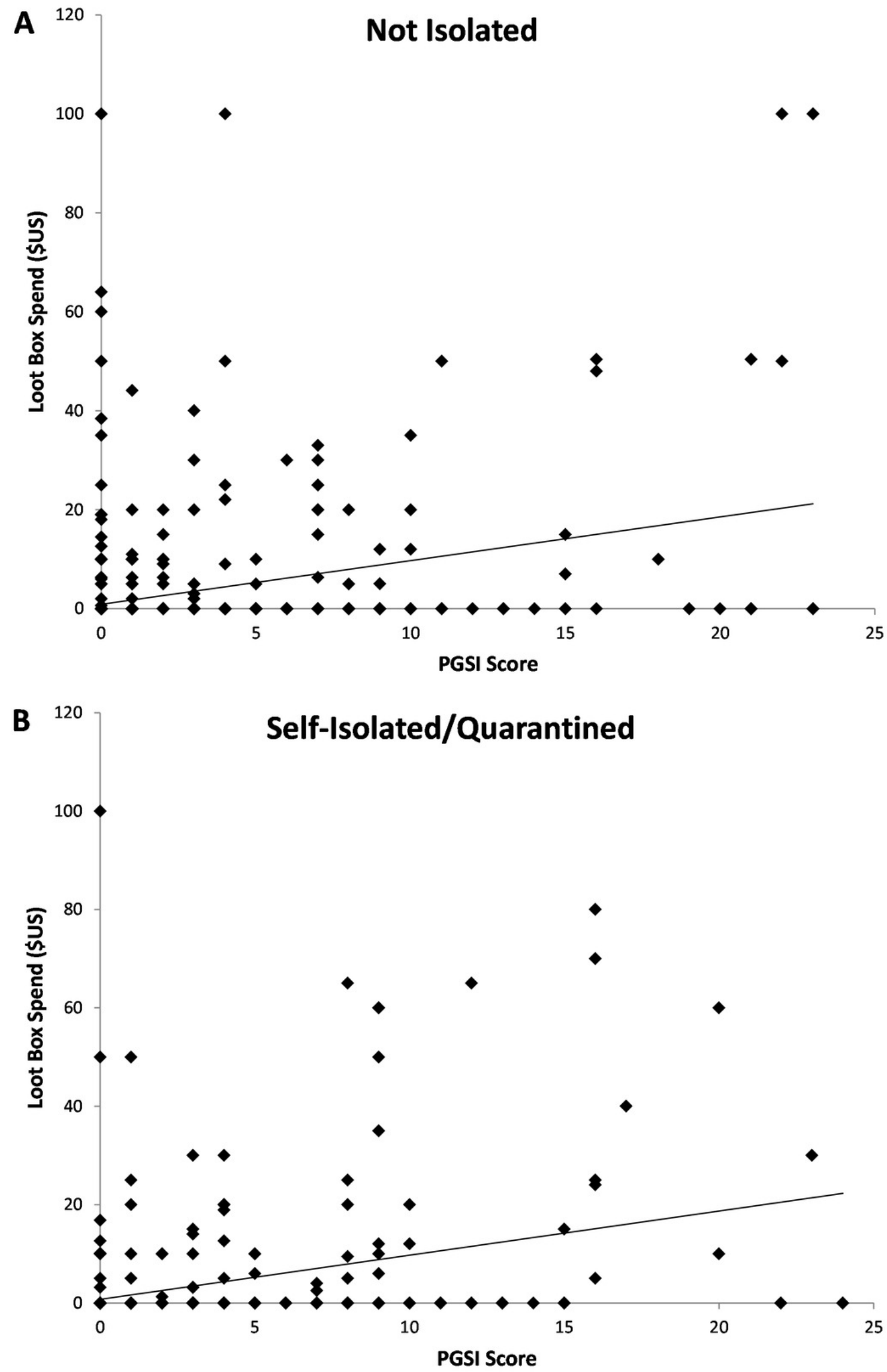


\section{Figure 2}

Loot Box spending split by PGSI group and whether or not participants were SelfIsolated or Quarantined.

There was a significant main effect of PGSI group, $F(3,1,131)=34.679, p<.001$. Planned comparisons showed that non-problem gamblers spent significantly less than low-risk gamblers, $\mathrm{t}(955)=1.987, p=.024, d=0.170$, low-risk gamblers did not spend less than moderate-risk gamblers, $t(420)=0.038, p=.485, d=0.006$, but moderate-risk gamblers did spend less than problem-gamblers $t(185)=5.986, p<.001, d=0.548$. Error bars denote Standard Error.

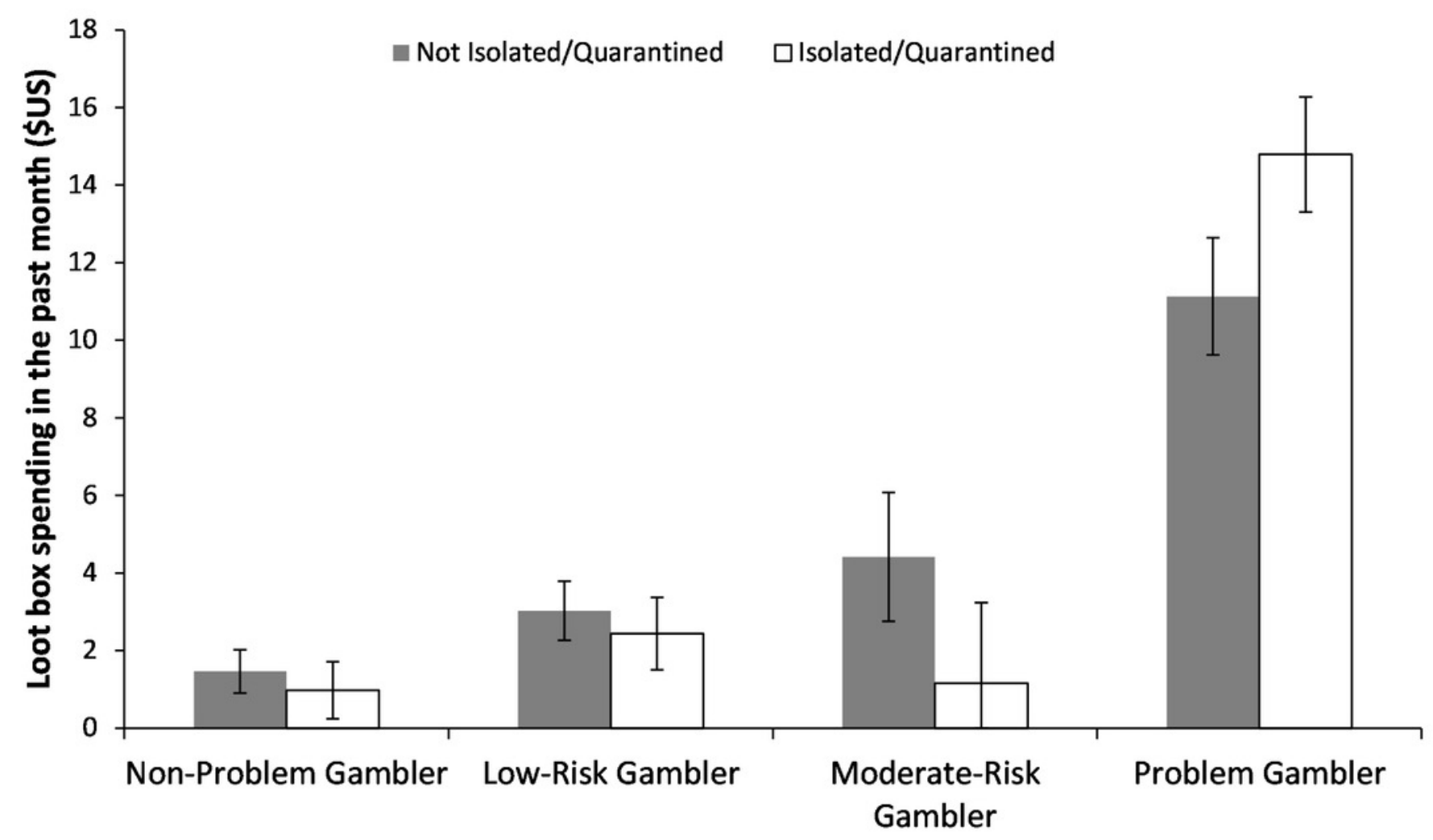

Problem Gambling Status 


\section{Table 1 (on next page)}

Sample demographics split by country.

Participant numbers, mean age, and modal gender for participants in Aotearoa New Zealand, Australia and the United States. 
1 Table 1. Sample demographics split by country.

\section{Country}

Variable Aotearoa New Zealand $(n=41)$ Australia $(n=173)$ United States $(n=930)$

\begin{tabular}{llll}
\hline Mean Age & $34.4(S D=10.2)$ & $30.9(S D=9.6)$ & $31.3(S D=10.7)$
\end{tabular}

Modal Gender

Male $(n=24)$

Male $(n=109)$

Male $(n=486)$

2 


\section{Table 2 (on next page)}

Associations between Contamination Concern and Problematic Gaming Scales.

Associations between Contamination Concern and Problematic Gaming Scales for All

Respondents (first column), Participants Not Self-Isolated or Quarantined (second column), and Self-Isolated or Quarantined (third column). Z-tests (column four) reported for the difference between Not-Isolated/Quarantined vs Self-Isolated/Quarantined. Correlations reported in Spearman's Rho. 
1 Table 2. Associations between Contamination Concern and Problematic Gaming Scales for All

2 Respondents (first column), Participants Not Self-Isolated or Quarantined (second column), and Self-

3 Isolated or Quarantined (third column). Z-tests (column four) reported for the difference between Not-

4 Isolated/Quarantined vs Self-Isolated/Quarantined. Correlations reported in Spearman's Rho.

\section{Contamination Concern}

\begin{tabular}{lcccc} 
& \multicolumn{1}{c}{ All } & Not Self-Isolated & Self-Isolated or & Z-test for \\
& Respondents & or Quarantined & Quarantined & difference \\
\hline Loot Box Spend & $.163^{* *}$ & $.133^{* *}$ & $.190^{* *}$ & $\mathrm{Z}=0.998$, \\
& & & & $p=.319$ \\
RLI & $.247^{* *}$ & $.202^{* *}$ & $.314^{* *}$ & $\mathrm{Z}=1.977$, \\
& & & & $p=.048^{*}$ \\
IGD & $.263^{* *}$ & $.239^{* *}$ & $.297^{* *}$ & $\mathrm{Z}=1.028$, \\
& & & & $p=.426$ \\
\hline
\end{tabular}

${ }^{*} p<.05, * * p<.001$ 